

\section{DISCLAIMER}

This document was prepared as an account of work sponsored by an agency of the United States Government. Neither the United States Government nor the University of California nor any of their employees. makes any warranty, express or implied. or assumes any legal liability or responsibility for the accuracy, completeness, or usefulness of any information. apparatua product, or process disclosed. or represents that its use would not infringe privately owned rights. Reference herein to any specilic commercial products. process. or service by trade name trademark. mannfacturer, or otherwise. does not necessarily constitute or imply its endorsement. recommendation. or favoring by the United States Government or the University of California. The views and opinions of authors expressed herein do not necessarily state or reflect those of the l'nited States Government or the University of California. and shall not be used for advertising or product endorsement purposes. 


\title{
POLLUTION CONTROL APPLICATIONS OF PULSED POWER TECHNOLOGY
}

\author{
B. M. Penetrante \\ Lawrence Livermore National Laboratory \\ L-417, 7000 East Avenue \\ Livermore, CA 94550 USA
}

\begin{abstract}
$\underline{\text { Abstract }}$
Much of the activity and growth in the field of pulsed power technology has been spawned by government-sponsored research for military applications. During the last two decades significant advances have been made in pulsed power modulators and accelerators. Pollution control systems for large industrial applications could benefit a great deal by exploiting the results of this research and development. In this paper I will present the history of how pulsed power technology got involved in pollution control applications. Emphasis will be placed on the application of pulsed power to pollution control in utility and industrial coal-fired power plants. The use of pulsed techniques for improving the efficiency of electrostatic precipitators will first be discussed; then the parallel developments in electron beam and pulsed corona processing for flue gas treatment will be presented. Pulsed power techniques are essential as supporting technologies for these advanced pollution control methods. To illustrate the large scale of these applications, I will discuss the power requirements of these methods.
\end{abstract}

\section{Introduction}

Acid rain is now recognized as a serious environmental problem. Nitrogen oxides $\left(\mathrm{NO}_{\mathbf{x}}\right)$ and sulfur dioxide $\left(\mathrm{SO}_{2}\right)$ are mainly responsible for this problem. In the US alone, the total emission of $\mathrm{NO}_{\mathrm{x}}$ amounts to 24 million tons per year. About $53 \%$ of this is emitted from utility and industrial fuel combustion (see Fig. 1). The total US emissions of $\mathrm{SO}_{2}$ amounts to 29 million tons per year, $75 \%$ of which is emitted from industrial and utility fuel combustion (see Fig. 1). The Clean Air Act of 1990 demands that the $\mathrm{NO}_{x}$ emissions be reduced to 2 million tons per year ( $92 \%$ reduction), and the $\mathrm{SO}_{2}$ emissions be reduced to 10 millior, tons per year (66\% reduction). The problem of acid rain gas emissions exists, not only in the US, but also worldwide. In the absence of adequate control equipment, the worldwide emissions to the atmosphere are 250 million tons of $\mathrm{SO}_{2}$ per year and 150 million tons of $\mathrm{NO}_{x}$ per year. In addition there is the problem of solid particulate emissions. Even with particulate removal devices having an average removal efficiency of $99 \%$, the worldwide emission to the atmosphere is still 30 million tons of solid particulates per year. Forecasts suggest that by year 2000 , the world coal consumption will increase by $35 \%$. To keep the total emissions of solid particulates constant, the collection surface of electrostatic precipitators have to be doubled.
TOTAL U.S. EMISSIONS OF $\mathrm{NO}_{x}$

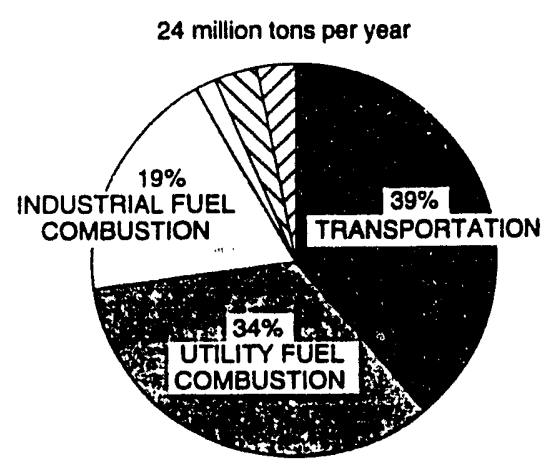

reduce to 2 million tons per year

TOTAL U.S. EMISSIONS OF $\mathrm{SO}_{2}$ 29 million tons per year

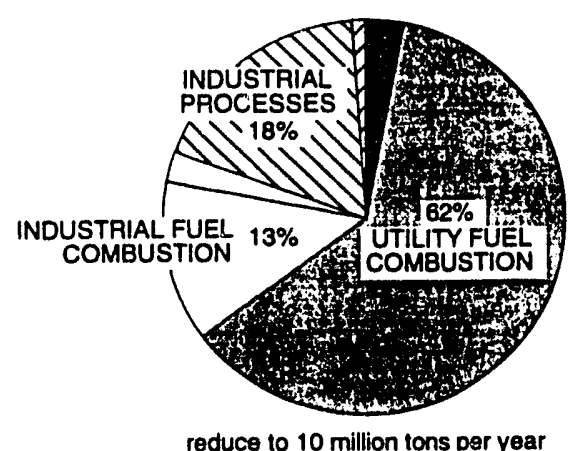

reduce to 10 million tons per year

Figure 1. Contributions to the total US emissions of $\mathrm{NO}_{x}$ and $\mathrm{SO}_{2}$.

The impact of these pollution problems is aggravated because the emissions are mainly released by point sources clustered together in industrialized countries. There are many inethods already available for dealing with these problems. However, the increasing level of emissions and the ever increasing restrictions make it more and more expensive to meet the government regulations designed to protect our environment. Pulsed power technology will become very important in dealing with these environmental problems.

The application of pulsed power to pollution control is not limited to $\mathrm{NO}_{\mathrm{x}} / \mathrm{SO}_{2} /$ particulate removal in power plants. The emphasis of this paper is on the treatment of flue gas emissions from power plants because this is a good example of a very large scale application of pulsed power. This particular application represents a big challenge from the point of view of both the huge market and required technology developments [1]. 


\section{Historical Overview}

In this section I will give a historical overview of how pulsed power technology got involved in pollution control. There are three parallel device developments that make pulsed power an important factor in pollution control: electrostatic precipitation, electron beam processing, and pulsed corona processing. Each of these pollution control methods has been influertial in promoting the use of pulsed power.

The commercial implementation of electrostatic precipitation dates back to the developments by F. G. Cottrell in 1905. At the time he used an ac transformer with a mechanical rectifier to supply the high-voltage, unidirectional current required. Today the method and equipment for supplying the high-voltage power still determine in large part the performance of electrostatic precipitators (see Fig. 2).

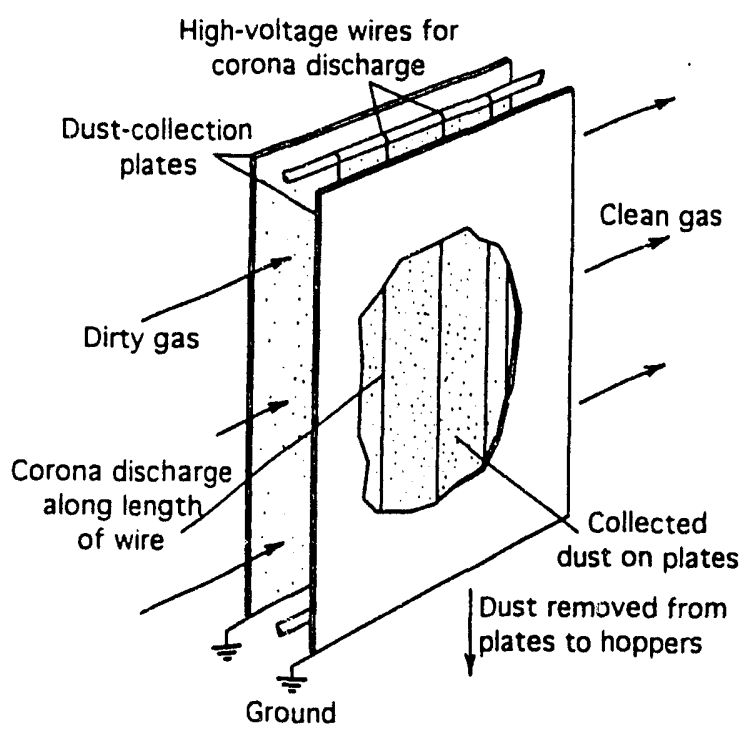

Figure 2. Simplest form of an electrostatic precipitator. When a high voltage is applied to the wire, the electric field created produces a corona region consisting of electrons and ions. The drift field established between the corona region and the coliection plate extracts ions. These ions interact with the particulates, imparting charge to the dust which is then driven to the collecting plate. Maximum particle collection requires maximum charges on the particles and maximum precipitation fields. Large particle charges can be attained only by applying very high peak voltages, while rapid collection of the charges requires high time-averaged values of the voltage.

The collection efficiency of electrostatic precipitators increases rapidly with increasing values of the drift velocity of charged particles in the precipitator electric field. The drift velocity increases as the product of the charging field and the collecting field, which in turn, are determined by the voltage waveform. Full-wave and halfwave voltages have higher sparking values than $\mathrm{dc}$ voltage and are much more stable in operation. In 1952 , H. J. White proposed the use of pulsed systems in electrostatic precipitators [2]. He recognized that pulsed systems could be used to optimize precipitator efficiency by allowing one to precisely adjust and control both the duration and frequency of the current pulses. The use of pulsed power made it possible to achieve higher peak voltage and higher sparking voltage. He used a rotating spark gap, with $200-400 \mathrm{~Hz}$ repetition frequency, pulse length of $100 \mu \mathrm{s}$, peak voltage of $70 \mathrm{kV}$, average current of $300 \mathrm{~mA}$ and an output power of $15 \mathrm{~kW}$. This led to an increase in the precipitation efficiency without having to increase the area of the collecting electrodes. Furthermore, White demonstrated that pulsed powering led to a higher over-all electrical efficiency (70\%). Unfortunately, attempts to implement pulsed powering was hampered by the available high-voltage switching technology.

In 1970 the Ebara Corporation in Japan conducted the first batch tests of electron beam processing for the simultaneous removal of $\mathrm{NO}_{x}$ and $\mathrm{SO}_{2}$ from flue gases. In this process, the high energy electrons produce a copious supply of ions and free radicals. The radicals, particularly the $\mathrm{OH}$ radical (see Fig. 3), react with $\mathrm{SO}_{2}$ and $\mathrm{NO}_{x}$ to form sulfuric and nitric acid, respectively. These acids are subsequently neutralized by additives such as ammonia or calcium hydroxide. The resulting by-products are typically dry and can be removed by means of conventional particle collectors such as an electrostatic precipitator or baghouse. With an ammonia additive, the $\mathrm{SO}_{2}$ and $\mathrm{NO}_{x}$ are converted to ammonium sulfate and ammonium nitrate, which are important agricultural fertilizer components (see Fig. 4).

Between 1970 and 1980, both laboratory and plant tests of electron beam processing were corducted by Ebara, the Japan Atomic Energy Research Institute and the University of Tokyo. Some of these tests were conducted with flue gas flow rates of up to $10,000 \mathrm{Nm}^{3} / \mathrm{h}$ (normal meters cubed per hour). In the USA, Research-Cottrell, in 1979-1980, conducted bench scale tests to evaluate the technical and economical feasibility of electron beam processing.

Between 1981 - 1982, several pilot plant and iull-scale tests of pulsed powering for electrostatic precipitatisrs were conducted in both the US and Japan. The US tests showed performance enhancement up to a factor of 3 while the Japanese tests showed performance enhancertent up to a factor of 5 .

The high capital cost of accelerators and $x$-ray hazard associated with electron-beam processing motivated studies into alternate plasma-based technologies such as those utilizing electrical discharges. In 1981, S. Masuda led experiments at the University of Tokyo to investigate the possibility of enhancing the $\mathrm{NO}_{x} / \mathrm{SO}_{2}$ removal efficiency of the electron-beam method by applying an electric field to regenerate energetic electrons in the plasma [3]. It was found that pulsed electric fields could be very effective when a corona discharge was created, even when the electron beam was switched off. This was the birth of the pulsed corona method for flue gas treatment. The pulsed corona method represented an apparently more economical approach by having the advantage of a low retrofit cost since it can use the same wire-plate electrode arrangement as in existing electrostatic precipitators. 


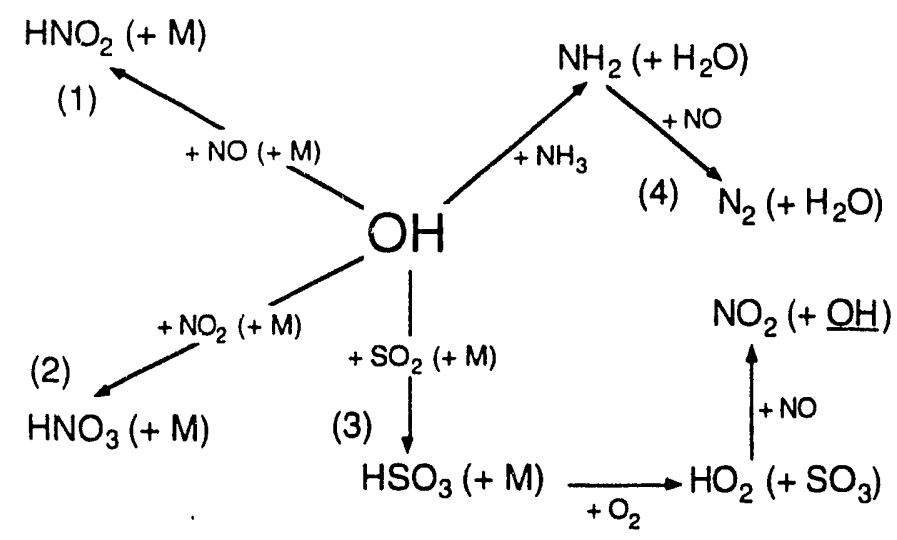

Figure 3. The $\mathrm{OH}$ radical plays a key role in the simultaneous removal of $\mathrm{NO}_{x}$ and $\mathrm{SO}_{2}$ in the presence of water vapor and ammonia. Route (1) is only partially effective, since $\mathrm{HNO}_{2}$ is liable to heterogeneous decomposition into $\mathrm{NO}$ and $\mathrm{NO}_{2}$. Route (2) is the most important source of nitric acid and ammonium nitrate. Route (3) replaces $\mathrm{OH}$ by $\mathrm{HO}_{2}$, which is needed for NO oxidation, and recycles $\mathrm{OH}$. Route (4) replaces $\mathrm{OH}$ by $\mathrm{NH}_{2}$, which reduces $\mathrm{NO}$. High energy electrons from electron beam irradiation are very effective in producing $\mathrm{OH}$ radicals.

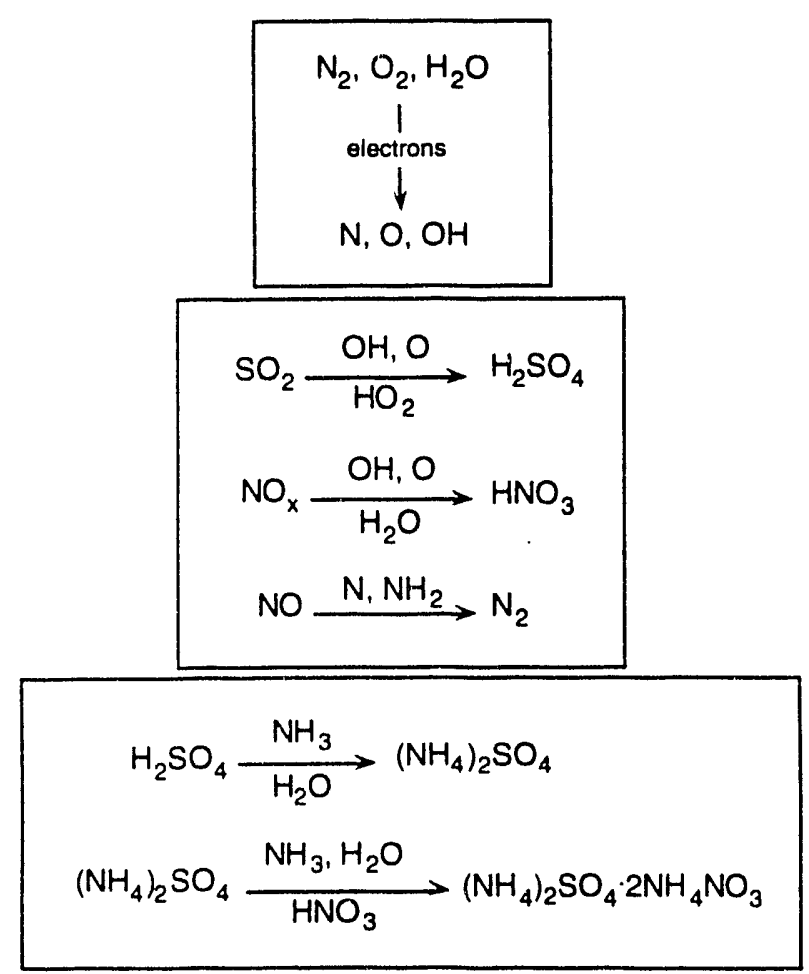

Figure 4. Simplified model of reaction mechanisms for the simultaneous removal of $\mathrm{SO}_{2}$ and $\mathrm{NO}_{\mathrm{x}}$ from flue gas by electron beam irradiation. Stage 1 represents radical production from the interaction of electrons with the flue gas. Stage 2 represents the conversion of $\mathrm{SO}_{2}$ and $\mathrm{NO}_{\mathrm{x}}$ to their respective acids, and the reduction of NO to $\mathrm{N}_{2}$. Stage 3 represents the formation of salt by-products which are then collected by an electrostatic precipitator or baghouse. The same mechanisms apply to the pulsed corona process, but the relative amounts of initial radicals and final by-products are different because the mean electron energies are lower.
In 1984 - 1985 pilot plant tests of electron beam processing were conducted in the USA by ResearchCottrell. The tests were done for a coal-fired power plant with flue gas flow rates of up to $5,300 \mathrm{Nm}^{3} / \mathrm{h}$. Between 1984 and 1988, the Ebara Environmental Corp. also conducted pilot plant tests of electron beam processing in the USA, with flue gas flow rates of $8,000-24,0000 \mathrm{Nm}^{3} / \mathrm{h}$ from a coal-fired power plant [4]. Also in $1984-1985$, pilot plant tests of electron beam flue gas treatment were conducted in Germany, with gas flow rates of up to 20,000 $\mathrm{Nm}^{3} / \mathrm{h}$ from a coal-fired power plant.

Meanwhile in 1985, A. Mizuno from Japan visited Florida State University and collaborated in laboratoryscale studies using the pulsed corona method for the simultaneous removal of $\mathrm{NO}_{x}, \mathrm{SO}_{2}$ and particulates [5]. At around the same time, the Italian national power company, ENEL, independently conducted small pilot plant tests of pulsed corona processing by retrofitting their electrostatic precipitators. Tests were conducted for a flue gas flow rate of $100 \mathrm{Nm}^{3} / \mathrm{h}$ from a coal-fired power plant. Ten electrostatic precipitators of $20 \mathrm{~cm}$ diameter and $1.5 \mathrm{~m}$ length were used, with voltage pulses of $300 \mathrm{~Hz}$ repetition frequency, $600 \mathrm{~ns}$ pulse length, risetime of $100-300 \mathrm{~ns}$ and peak voltage of $90 \mathrm{kV}$. It is important to note that these ENEL tests have become the sole basis for the assessment of the electrical technology requirements of the pulsed corona process for applications to flue gas cleanup in actual power plants.

In 1985, ENEL tested the pulsed powering of industrial-size electrostatic precipitators [6]. The tests were conducted with flue gas flow rates of $175,000 \mathrm{Nm}^{3} / \mathrm{h}$, and used pulses of $300 \mathrm{~Hz}$ repetition rate, $60-240 \mu \mathrm{s}$ pulse length, average current of $400 \mathrm{~mA}$ and peak voltage of 180 $\mathrm{kV}$. The tests demonstrated precipitator performance enhancement of a factor of 5 .

In 1988, ENEL conducted larger pilot plant tests of the pulsed corona process for $\mathrm{NO}_{\mathrm{x}} / \mathrm{SO}_{2}$ removal using a 1,000 $\mathrm{Nm}^{3} / \mathrm{h}$ flue gas flow rate [7]. The pulses used were $300 \mathrm{~Hz}$, risetime of $200 \mathrm{~ns}$, pulse length of $1 \mu \mathrm{s}$, peak voltage of 150 $\mathrm{kV}$ and output power of $20 \mathrm{~kW}$. Since that time, ENEL has been working on a scale-up to $10,000 \mathrm{Nm}^{3} / \mathrm{h}$, but progress seems to have been hampered by the absence of suitable pulsed power generators $(100 \mathrm{kV}, 100 \mathrm{~kW}, 300 \mathrm{~Hz}$, pulse length less than $1 \mu \mathrm{s}$, and greater than $75 \%$ electrical efficiency).

Back in Japan, three advanced pilot plani tests are now being conducted for electron-beam treatmant of flue gases [8]. These tests were started in 1991. One objective of these tests is to optimize the electron beam process for the treatment of flue gases from utility coal-fired boilers. The other objective is to expand the applications of the electron beam process to other kinds of gases; for example, incinerator flue gas, diesel truck exhaust gas, and gases containing various kinds of VOCs. From these pilot projects it is expected that sufficient information will be obtained to design, construct and operate a commercial facility. At the Ebara Corporation research facility in Fujisawa, the electron-beam process is being fine tuned for commercial use, and testing is being performed on 
incinerator gases and diesel truck exhaust gases. At the Chubu Electric Plant facility in Nagoya, studies are focused on process optimization, equipment reliability, and byproduct handling. At the Tokyo Metropolitan tunnel facility, testing is being done to optimize a high-flow

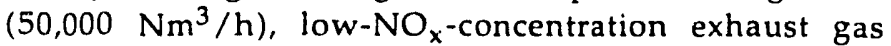
treatment system in a vehicle tunnel under Tokyo Bay. In addition, the gases are analyzed for other hydrocarbons to determine the effects of the electron-beam process on unburned hydrocarbons.

Large pilot plant tests of electron beam processing also continue to be conducted in other countries. In Poland, tests started in 1991 are being conducted with flue gas flow rates of $20,000 \mathrm{Nm}^{3} / \mathrm{h}$.

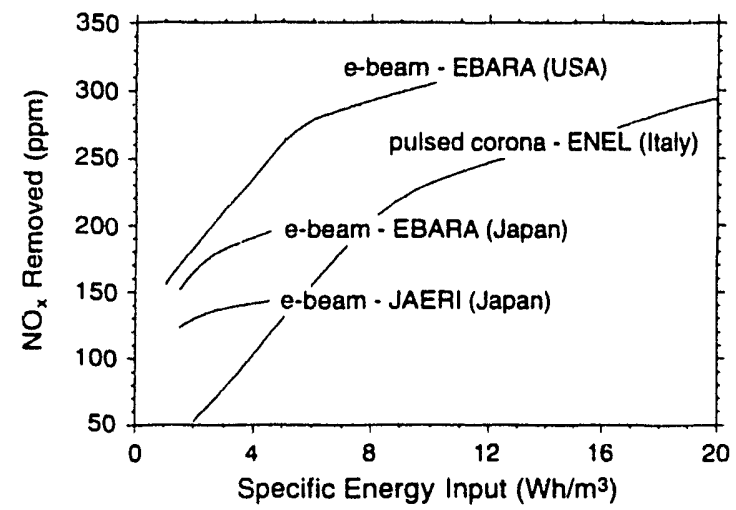

Figure 5. Amount of $\mathrm{NO}_{x}$ removed as a funciion of the specific energy input. The pulsed corona result obtained at ENEL (1taly) [7] was for initial $\mathrm{NO}_{x}$ of $300-550 \mathrm{ppm}$, and gas flow rates of $500-600 \mathrm{Nm}^{3} / \mathrm{h}$. The electron beam result obtained at Ebara (USA) [4] was for initial $\mathrm{NO}_{x}$ of $270-390 \mathrm{ppm}$, and gas flow rates of 4000-5200 scfm. The result obtained at Ebara (Japan) [8] used 3-stage electron beam irradiation with initia $\mathrm{NO}_{\mathrm{x}}$ of around $200 \mathrm{ppm}$. The result obtained at JAERI (Japan) [9] used triple stage irradiation with initial $\mathrm{NO}_{x}$ of $150 \mathrm{ppm}$ and gas flow rate of $15 \mathrm{Nliter} / \mathrm{min}$.

\section{Power Requirements and Costs}

The cost of implementation underlies almost all of the decision-making in selecting the technology for pollution control. Some cost comparison studies show that both the electron beam process and the pulsed corona process are competitive to "conventional" methods. In a recent EPRI study [10], the conclusion was "...for retrofits, the electron beam process rated equivalent or preferable to FGD/SCR (Flue Gas Desulfurization/ Selective Catalytic Reduction)." A study [11] was recently sponsored by the Japanese Ministry of International Trade and Industry to perform technical and economic assessments of the pulsed corona process for coal-burning utility boilers. The pulsed corona process was compared to the conventional calcium-gypsum process for $\mathrm{deSO}_{x}$ combined with the ammonia-catalytic process for deNO $\mathrm{N}_{\mathrm{x}}$. A comparison was also made to the electron beam $\operatorname{deNO} \mathrm{N}_{x} / \mathrm{deSO}_{x}$ process. The study committee concluded that the pulsed corona method deserves development as the next generation technology for the removal of $\mathrm{SO}_{2}$ and $\mathrm{NO}_{\mathrm{x}}$ in utility boiler plants.
In this section I will present the power requirements and cost estimates of both the electron beam process and the pulsed corona process based on the best results achieved in pilot plant tests.

Consider a $500 \mathrm{MW}$ power plant burning 194 tons per hour of midwestern coal. The typical flue gas flow rate is $10^{6} \mathrm{scfm}$ or $4.7 \times 10^{8} \mathrm{~cm}^{3} / \mathrm{s}$. The gas is polluted with 350 ppm of $\mathrm{NO}_{x}$ and 2000 ppm of $\mathrm{SO}_{2}$. Both laboratory and pilut plant tests show that it is relatively easy to remove $\mathrm{SO}_{2}$. The power consumption for the combined removal of $\mathrm{NO}_{x}$ and $\mathrm{SO}_{2}$ is determined mainly by the removal of $\mathrm{NO}_{\mathbf{x}}$. The required rate of $\mathrm{NO}_{\mathbf{x}}$ removal is

$$
\begin{aligned}
& 350 \mathrm{ppm} \times 10^{-6} \times 4.7 \times 10^{8} \mathrm{~cm}^{3} / \mathrm{s} \times 2 \times 10^{19} \text { molecules } / \mathrm{s}= \\
& 3.3 \times 10^{24} \mathrm{NO}_{\mathrm{x}} \text {-molecules per second }
\end{aligned}
$$

The best value of specific energy consumption for deNO achieved by the electron beam process is

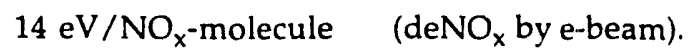

The power requirement for the electron beam process is thus

$$
\begin{aligned}
& 14 \mathrm{eV} / \mathrm{NO}_{\mathrm{x}} \times 3.3 \times 10^{24} \mathrm{NO}_{\mathrm{x}} / \mathrm{s}=4.6 \times 10^{25} \mathrm{eV} / \mathrm{s}= \\
& 7.4 \mathrm{MW}
\end{aligned}
$$

This represent $1.5 \%$ of the power plant ouiput.

The best value of specific energy consumption for deNO ${ }_{x}$ achieved by the pulsed corona process is

$$
50 \mathrm{eV} / \mathrm{NO}_{\mathbf{x}} \text {-molecule (deNO }{ }_{x} \text { by pulsed corona). }
$$

The power requirement for the pulsed corona process is thus

$$
\begin{aligned}
& 50 \mathrm{eV} / \mathrm{NO}_{\mathrm{x}} \times 3.3 \times 10^{24} \mathrm{NO}_{\mathrm{x}} / \mathrm{s}=1.7 \times 10^{26} \mathrm{eV} / \mathrm{s}= \\
& 26.4 \mathrm{MW}
\end{aligned}
$$

This represent $5.3 \%$ of the power plant output.

Cost analysis shows that in order for electron beam processing to be competitive with the FGD/SCR method, the accelerator has to cost around $\$ 2$ per watt. This implies that a $500 \mathrm{MW}$ power plant will require a $7.4 \mathrm{MW}$ accelerator (or set of accelerators) costing $\$ 15$ million. Assuming that pulsed power generators can be manufactured at a cheaper cost of $\$ 1$ per watt, the same $500 \mathrm{MW}$ power plant will require a $26.4 \mathrm{MW}$ pulsed power system costing $\$ 26$ million.

\section{Conclusions}

Three points should be noted in the historical overview presented in this paper. First, pulsed power has already been successfully demonstrated in a large scale for improving the efficiency of electrostatic precipitators. Pulsed power will undoubtedly become essential as the world consumption of coal for energy production increases. Second, many pilot plant tests of electron beam processing for $\mathrm{NO}_{\mathbf{x}} / \mathrm{SO}_{2}$ removal have been, and continue 
to be, conducted around the world. Coal-fired pilot plant tests with gas flow rates as large as $25,000 \mathrm{Nm}^{3} / \mathrm{h}$ have been conducted. Scale-up of electron beam accelerators using pulsed techniques are now being conducted. The use of pulsed power techniques could lead to modular and cheaper electron beam accelerators. Third, demonstration of the pulsed corona process for $\mathrm{NO}_{x} / \mathrm{SO}_{2}$ removal in a large scale has been hampered by the absence of suitable pulsed power generators. The pulsed power requirements for pulsed corona reactors are much more demanding than those for electrostatic precipitators. The largest pilot plant test conducted by ENEL is $1,000 \mathrm{Nm}^{3} / \mathrm{h}$. As mentioned before, the ENEL tests have become the sole basis for the assessment of the electrical technology requirements of the pulsed corona process. Larger scale tests are essential in order to learn not only what the scalability of the process is, but also what the typical investment and operating costs are at full-scale industrial facilities.

\section{Acknowledgments}

This work was performed at I.awrence Livermore National Laboratory under the auspices of the U.S. Department of Energy under Contract Number W-7405ENG-48, with support from the Advanced Energy Projects Division of the Office of Energy Research.

\section{References}

[1] G. Lister, "Plasmas Join the Fight Against Acid Rain," Physics World (Dec. 1992) pp. 19-20.

[2] H. J. White, "A Pulse Method for Supplying HighVoltage Power for Electrostatic Precipitation," AIEE Trans. vol. 71, pp. 326-329 (1 352 ).

[3] S. Masuda, M. Hirano, and K. Akutsu, "Enhancoment of electron beam denitrization process by means of electric field," Radiat. Phys. Chem. vol. 17, pp. 223-228 (1981).

[4] N. W. Frank and S. Hirano, "The History of Electron Beam Processing for Environmental Pollution Control and Work Performed in the United States," presented at the NATO Advanced Research Workshop on Non-Thermal Plasma Techniques for Pollution Control Cambridge, UK, Sep. 21-25, 1992.

[5] A. Mizuno and J. S. Clements, "Method of Removing $\mathrm{SO}_{2}, \mathrm{NO}_{x}$ and Particles from Gas Mixtures Using Sireamer Corona," U.S. Patent Number 4.695.358 (Sep. 22, 1987) Assignee: Florida State University.

[6] G. Dinelli and M. Rea, "Pulse Power Electrostatic Technologies for the Control of Flue Gas Emissions," L. Electrostatics vol. 25, 23-40 (1990).

[7] G. Dinelli, L. Civitano, and M. Rea, "Industrial Experiments on Pulse Corona Simultareous Removal of $\mathrm{NO}_{x}$ and $\mathrm{SO}_{2}$ from Flue Gas," IEEE Irans. Ind. Appl. vol. 26, pp. 535-541 (1990).

[8] A. Maezawa and M. Izutsu, "Application of E-Beam Treatment to Flue Gas Cleanup in Japan," presented at the NATO Advanced Research Workshop on Non-Thermal Plasma Techniques for Pollution Control Cambridge, UK, Sep. 21-25, 1992.

[9] O. Tokunaga and H. Namba, "Experiments of Chemical Reactions in Electron-Beam-Induced $\mathrm{NO}_{x} / \mathrm{SO}_{2}$ Removal," presented at the $\mathrm{NATO}$ Advanced Research Workshop on Non-Thermal Plasma Techniques for Pollution Control Cambridge, UK, Sep. 21-25, 1992.

[10] Pasha Publications (Dec. 23, 1991), Coal \& Synfuels Technology, Source: Electric Power Research Institute.

[11] "Study Report on Novel Dry DeNO $/$ DeSO $_{x}$ Technology for Cleaning Combustion Gases from Utility Thermal Power Plant Boilers Using Pulse Corona Induced Plasma Chemical Process," Association of Mechanical Industries Japan, Research Institute of Energy Engineering (May 1991). 

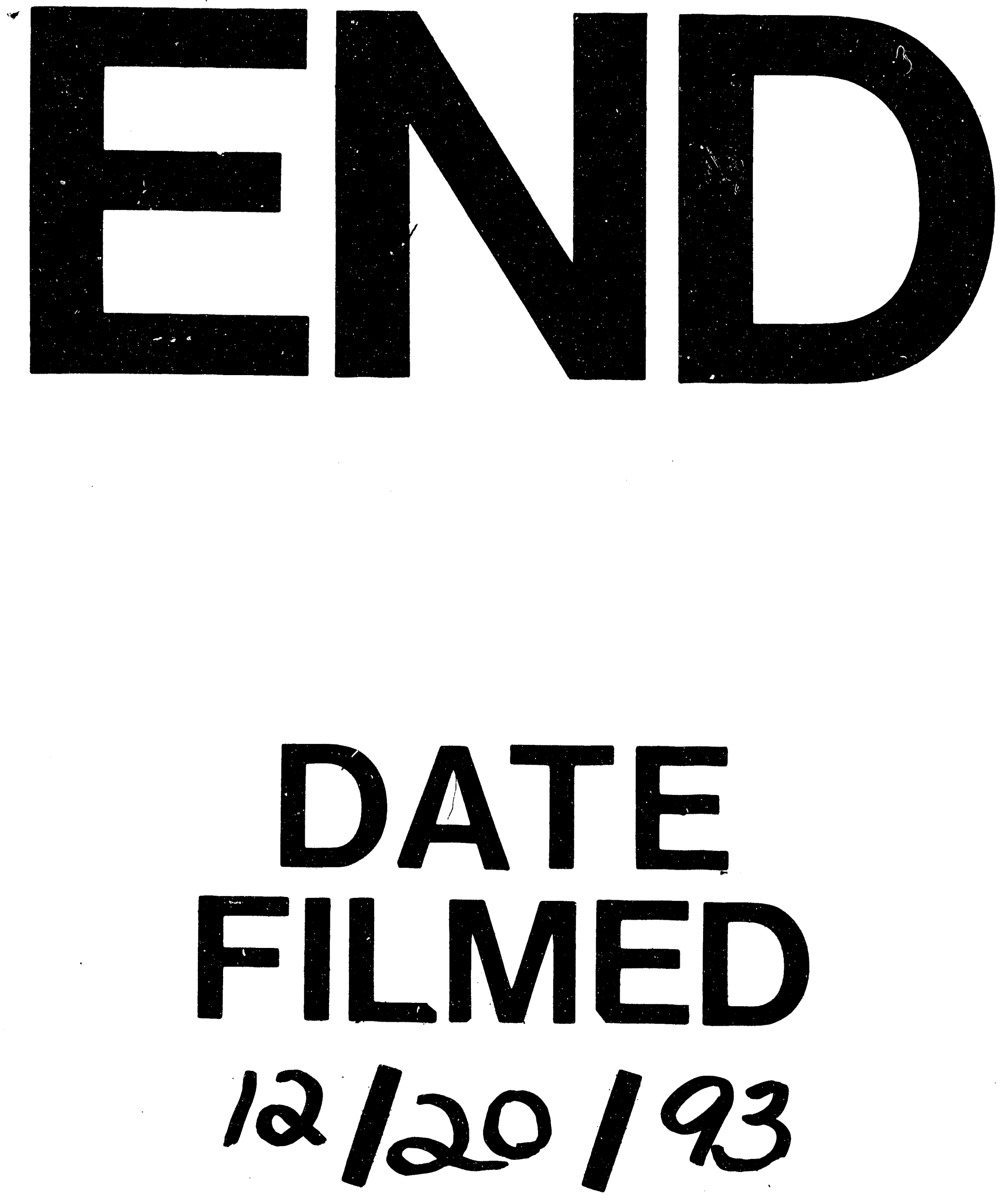

1 


$$
\text { . }
$$

